\title{
Site Resource Inventories - a Missing Link in the Circular City's Information Flow
}

\author{
Gösta Baganz $^{1,2}$, Gundula Proksch ${ }^{3}$, Werner Kloas ${ }^{1,4,5}$, Wolf Lorleberg ${ }^{6}$, Daniela Baganz ${ }^{1}$, Georg Staaks ${ }^{1}$, and \\ Frank Lohrberg 7 \\ ${ }^{1}$ Leibniz-Institute of Freshwater Ecology and Inland Fisheries, Berlin, Germany \\ ${ }^{2}$ Faculty of Architecture, RWTH Aachen University, Aachen, Germany \\ ${ }^{3}$ College of Built Environments, University of Washington, Seattle, WA, USA \\ ${ }^{4}$ Albrecht Daniel Thaer-Institute of Agricultural and Horticultural Sciences, Berlin, Germany \\ ${ }^{5}$ Institute of Biology, Humboldt University, Berlin, Germany \\ ${ }^{6}$ Fachbereich Agrarwirtschaft, South Westphalia University of Applied Sciences, Soest, Germany \\ ${ }^{7}$ Institute of Landscape Architecture, RWTH Aachen University, Aachen, Germany
}

Correspondence: Gösta Baganz (g.baganz@igb-berlin.de)

Received: 8 June 2020 - Revised: 9 August 2020 - Accepted: 18 August 2020 - Published: 1 October 2020

\begin{abstract}
A circular city builds upon the principles of circular economy, which key concepts of reduce, reuse, recycle, and recover lead to a coupling of resources: products and by-products of one production process become the input of another one, often in local vicinity. However, sources, types and available quantities of underutilised resources in cities are currently not well documented. Therefore, there is a missing link in the information flow of the circular city between potential users and site-specific data. To close this gap, this study introduces the concept of a site resource inventory in conjunction with a new information model that can manage the data needed for advancing the circular city. A core taxonomy of terms is established as the foundation for the information model: the circular economy is defined as a network of circular economy entities which are regarded as black boxes and connected by their material and energy inputs and outputs. This study proposes a site resource inventory, which is a collection of infrastructural and buildingspecific parameters that assess the suitability of urban sites for a specific circular economy entity. An information model is developed to manage the data that allows the entities to effectively organise the allocation and use of resources within the circular city and its material and energy flows. The application of this information model was demonstrated by comparing the demand and availability of required alternative resources (e.g. greywater) at a hypothetical site comprising a commercial aquaponic facility (synergistic coupling of fish
\end{abstract}

and vegetables production) and a residential building. For the implementation of the information model a proposal is made which uses the publicly available geodata infrastructure of OpenStreetMap and adopts its tag system to operationalise the integration of circular economy data by introducing new tags. A site resource inventory has the potential to bring together information needs and it is thus intended to support companies when making their business location decisions or to support local authorities in the planning process.

\section{Introduction}

The UN has set out Sustainable Development Goals (SDG) to achieve a better and more sustainable future for all. In an urban context, SDG11 (Sustainable Cities and Communities) and SDG12 (Responsible Consumption and Production) are of paramount importance when considering current problems such as climate change, population growth, and urbanisation, as well as the over-exploitation and pollution of natural resources (UN, 2019). The European Commission has adopted a new Circular Economy Action Plan - one of the main elements of the European Green Deal, Europe's new agenda for sustainable growth. The new Action Plan announces initiatives along the entire life cycle of products, targeting for example their design, promoting circular economy processes, fostering sustainable consumption, and aiming to ensure that 
the resources used are kept in the EU economy for as long as possible (EC, 2020).

The concept of the Circular Economy (CE) has been defined as an economic system which operates at the micro (products, companies, consumers), meso (eco-industrial parks) and macro (city, region, nation and beyond) levels with the aim to accomplish sustainable development, thus simultaneously creating environmental quality, economic prosperity and social equity, to the benefit of current and future generations (Kirchherr et al., 2017). CE leads to a sustainable value creation through its integral technological elements and its associated characteristics (Jawahir and Bradley, 2016). However, others have highlighted the limitation and challenges of the $\mathrm{CE}$ concept with respect to environmental sustainability, including the critical definition of CE system boundaries and the challenges of managing CE material and energy flows between different organisations and sectors (Korhonen et al., 2018). It seems that some of these limitations can be overcome by an improved information flow within the CE, providing in particular better knowledge of the type, quantity, and spatial distribution of $\mathrm{CE}$ resources.

The circular city (CC) generally applies the concept, principles and functions of CE and is thereby enabled by digital technology and foundationally designed as a regenerative and even restorative urban living system (Sukhdev et al., 2019). The CC aims to eliminate the concept of waste and keep assets at their highest utility at all times (Katsou et al., 2020). Its key $3 R$ concept comprises reduce, reuse, and recycle (Langergraber et al., 2020) and can be extended to a $6 \mathrm{R}$ concept by recover, redesign and re-manufacture (Jawahir and Bradley, 2016). The CC leads to a coupling of resources: products and by-products of one process become the productive input of another (King et al., 2015). The 3R philosophy was underlined as an essential part of one core operational principle: closing the system, being crucial to accomplish the goals of CE (Suárez-Eiroa et al., 2019). In the following, the abbreviation $\mathrm{CE}$ is used in wider contexts of circular economy, while $\mathrm{CC}$ is used in reference to specific urban applications.

The actual integration of CE principles in cities and the scaling-up of networks of circular, interconnected companies within the $\mathrm{CC}$, whether by connecting (retrofitting) existing companies or by establishing new operations, is challenging and requires new tools for future planning. This study describes the basics of one such tool: a new information model that could provide and manage important datasets needed for advancing the circular city.

Food production is the greatest burden on the Earth's ecosystems (Willett et al., 2019; Albrecht et al., 2018); however, within the $\mathrm{CC}$, the food production sector has the potential to operate sustainably if resource-efficient technologies are used (Proksch, 2016; Buehler and Junge, 2016; Lohrberg et al., 2015; Blay-Palmer and Donald, 2006). Aquaponics, the coupled production of fish and vegetables, is one such food production technology (Kloas et al., 2015; Palm et al., 2018).

The present study introduces a methodology to improve the information flow in the $\mathrm{CC}$ and pursues three objectives: (1) To define a core taxonomy of CE terms as the basis for a CE information model. (2) To develop this information model for comparing demand and availability of required resources at a given site with aquaponics as a hypothetical example. And (3) to propose an implementation of the information model by the introduction of new tags into the OpenStreetMap public spatial data infrastructure.

Thus, this study shows how the proposed information model could help to embed an enterprise like aquaponics more successfully within the CC.

\section{Infrastructural Frameworks}

For the purpose of this study, the authors refer to conventional technical infrastructure as standard infrastructure. Standard infrastructure consists of utility grids for the supply of water, electricity, gas, or heat and the disposal of sewage and waste. The planning of such infrastructure is geared toward the requirements of the consumers (households, enterprises, institutions, etc.). In general, these are forecasted needs, which are determined on the basis of indicators such as population numbers, commercial development, and city structure. One important feature of these urban utilities is the standardisation of services. Where available, the standard infrastructure (water, electricity, or heat) is usually of consistent quality and has, if adequately dimensioned, a relatively small impact on the selection of a new business location (Howard, 2001) at least in most cities of the Global North (Coutard and Rutherford, 2016). However, the situation is different in the circular economy which attempts to utilise alternative resources such as storm water, greywater, excess heat and organic waste.

The sources, types and available quantities of these underutilised resources in cities are still widely unclear, they are currently not well-documented and there are no specific software applications for this purpose. Therefore, it is difficult for planners and CE actors to take advantage of these resources or strategically search for business locations and where they are available. The information model developed in this study (cf. Fig. 2), attempts to close the information gap between potential users and underutilised resources. It is a new approach and the necessary data has to be collected, managed, and distributed; but solving this problem might contribute to better resolution of the information flow - a key challenge in realising the CC. This becomes more important when Smart City concepts - which rely heavily on the availability of data - are to be integrated into the CC. The definition of the CC system boundaries must be done for each $\mathrm{CC}$ on the basis of its specific conditions; however a 
Table 1. Hypothetical Circular Economy Entities.

\begin{tabular}{lll}
\hline Entity name & Entity type & $\begin{array}{l}\text { Location } \\
\text { (point) }\end{array}$ \\
\hline Biogas Coop & Biogas plant & lat/lon* \\
Fine Fish \& Veggies & Aquaponics & lat/lon \\
Skyscraper 7 & Residential buildings & lat/lon \\
South Porcelain & Manufactory & lat/lon \\
\hline
\end{tabular}

* Position: latitude/longitude.

good approximation is the administrative border because the administrative responsibilities remain the same.

\section{Circular Economy Entities}

For the purpose of this study, circular economy is defined as a network of elements which can be seen as black boxes. These elements have a specific location and are connected by their resource inputs and outputs. The authors call each of these elements (or black boxes) a CE entity. The by-products of CE entities (often considered waste) are used as the inputs of other CE entities. These entities can be different in nature and could be grouped into types by their specific activities, e.g. aquaponics, brewery, etc.

While detailed economic considerations of the $\mathrm{CE}$ are not taken into account in this study, the assumption is that CE entities benefit economically from using previously unused resources and create a positive environmental impact. Some examples of CE entities which might use or provide underutilised resources are shown in Table 1: a residential building equipped with dual piping capable of supplying greywater separately, a manufactory which releases excess heat, an entity which accepts organic waste as input (biogas plants), and an aquaponic facility (Million et al., 2018; King et al., 2015).

Through an interconnected network of CE entities, the CC can increase the number of available alternative resources, bringing resources that were previously not available within the city's system boundaries into the $\mathrm{CC}$. This increases the CC's resilience due to decreased dependencies on resources from outside its system boundaries. On the other hand, the increased number of direct provider (output) to consumer (input) resource relationships in closed loops create increased mutual dependencies which can lead to greater vulnerability of the $\mathrm{CC}$. In order to foster resilience in the $\mathrm{CC}$, an adequate number and proportion of $\mathrm{CE}$ entities must be identified and incorporated.

\section{Aquaponics as a CE entity}

Aquaponics is the coupled production of fish and vegetables (Goddek et al., 2019). This resource efficient and sustainable food production technology is well suited to use CC's re- (a) Aquaponics (AP) as one black box

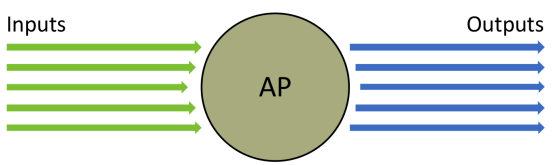

(b) Split: aquaculture (RAS) and hydroponics as four black boxes

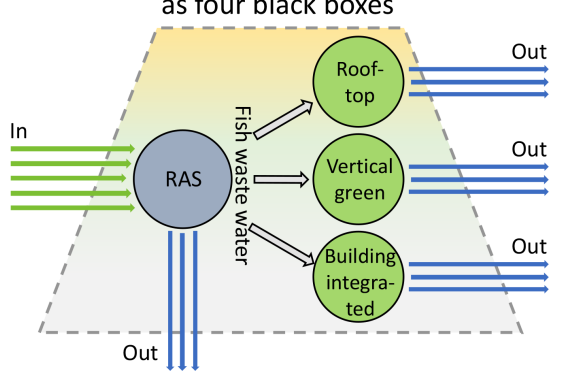

Figure 1. Black boxes: two use cases with (a) one respectively (b) four CE entities.

sources within urban and peri-urban agriculture (UPA) (Skar et al., 2019; Proksch and Baganz, 2020; Goddek and Körner, 2019; Keesman et al., 2019). This technology has inherent circular elements, as the fish effluent is used as an input (fertiliser) for the plant production unit. Regardless, this study focuses on the performance of the operation within a CE network in which each facility (CE entity) is a black box. If the elements of an aquaponics operation are split into separate units such as a recirculating aquaculture system (RAS), a hydroponic greenhouse, or vertical greening apparatus, all of these components would be considered discrete black boxes themselves, potentially with different owners or operators (cf. Fig. 1).

Although it is possible to abstract internal mechanisms as separate black boxes within a CE entity, this is precisely not the case with respect to spatial prerequisites; here, not only spatial parameters, but also socio-economic parameters must be taken into consideration. Surface area and spatial building-specific parameters (e.g. unused space, rooftop configuration) are resources, but they are not part of the material flow and are therefore not considered here at first. Due to the competition of different usages for the limited space available in cities, professional urban aquaponics is compelled to be lean and locally adapted business strategies are helpful to increase the profitability of such facilities (Baganz et al., 2020). In most locations, aquaponic operations require an enclosure, in the form of either a greenhouse or an indoor grow space with electrical lighting, in order to be run yearround as controlled environment agriculture (CEA). In cities, greenhouses can be installed on rooftops, as long as the host building can provide enough structural capacity and indoor growing facilities can be located within existing warehouses (Proksch et al., 2019). 


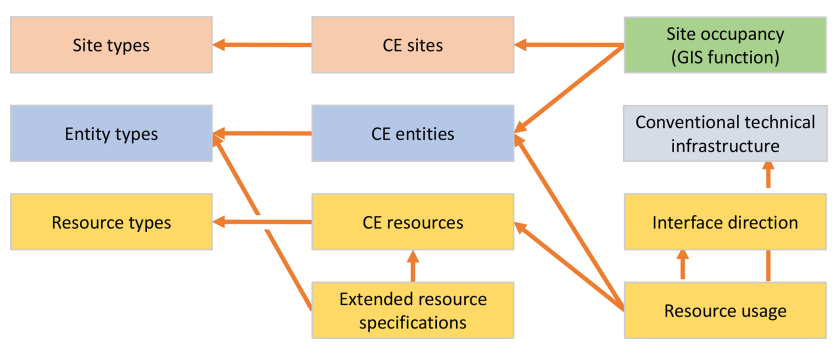

Figure 2. Core CE information model, arrow direction indicates access to model elements.

Models of aquaponic operations (Goddek and Körner, 2019; Karimanzira et al., 2016) and their accompanying control mechanisms (Reyes Lastiri et al., 2018; Witzel et al., 2019) can be used (1) to parameterise a facility, (2) to determine productivity, resource use (input) and, waste generation (output), and (3) to best fit a facility into the urban context of a CC for future planning. A CE entity such as an aquaponics facility regarded as a black box within the information model is characterised by its demand or provision of resources. Each resource or by-product of such a black box has certain key properties such as reliability (constant or intermittent supply), quality (level of treatment or processing required), and an interface direction (Fig. 2): input (required) or output (provided). Whereas the flow of every resource interface is unidirectional, each CE entity may own multiple interfaces, thus enabling bidirectional resource flows or feedback loops.

The resources are typified at the standard infrastructure level (e.g. thermal energy) and given a subtype (e.g. excess heat). Table 2 shows examples of records for an aquaponics operation considered as a CE entity. The types of all CE resources available in a given $\mathrm{CC}$ result in a resource catalogue, which is needed to classify and describe the resource flows within the $\mathrm{CC}$ in a structured way.

Some example records of a resource catalogue are displayed for aquaponics as a CE entity in Table 2. The aquaponic products fish and vegetables are not considered $\mathrm{CE}$ resources even if they are part of the urban metabolism since they only become resources after conversion (blackwater, food waste). However, whether resources are considered part of the CC system is subject to change. Inputs (cf. Fig. 1) are brought into the $\mathrm{CC}$ system by the usage of $\mathrm{CE}$ resources, whereas unused outputs represent the potential of the CC. For example, fish food is not listed in the catalogue because it is coming from outside the $\mathrm{CC}$ system boundaries. If, for example, there would be a producer of sustainable fish food within the $\mathrm{CC}$, the fish food would be considered a CC resource and input of the aquaponic facility; and the biomass by-products output of the aquaponic facility could be directed as input to the fish food producer as well, forming another closed, circular loop.

\section{Site Resource Inventory}

Considering the spatial distribution of CE resources in a city, there are spatial zones of interest, such as: (1) resource clusters, either emergent or planned, (2) specially designated areas or CE business zones, and (3) areas that are in focus for other reasons. These zones are referred to here as sites of a certain type, e.g. "urban area" and their characteristics are micro location factors within the CC. The spatial demarcation of such a site is flexible, depending on the respective requirements and all $\mathrm{CE}$ entities within the site make up the site occupancy (cf. Fig. 2).

For an investor or operator planning a new CE entity, it is crucial to link this operation with urban resources. Starting with the requirements of this planned CE entity with a known configuration at a given location, comprehensive information is needed on (1) the available infrastructure, (2) where other usable CE entities are located, and (3) what types, quantities and corresponding qualities of resources they might offer or demand. CE entities often require a location close to other suitable CE entities within the built environment to take advantage of synergies (greywater, fish waste water). However, CE entities can also take advantage of standard infrastructure to be connected over long distances to other $\mathrm{CE}$ resources (photovoltaic, excess heat).

At this point, the need for information necessary to connect complementary CE entities in the $\mathrm{CC}$ becomes obvious. This study proposes a site resource inventory, a collection of infrastructural and building-specific parameters to assess the suitability of potential urban sites for a CE entity. The following assumptions were made for a given site: (1) if possible, all CE entities and their resources are known, and (2) remote CE-sources are added via the standard infrastructure (utility grid). Different data sources must be used to reveal the urban resources available at a given site, as the effectiveness of the site resource inventory system depends on them. A hypothetical urban area "New Block" may serve as an instance, consisting of a commercial aquaponic facility which produces $21.5 \mathrm{ta}^{-1}$ fish and $42 \mathrm{ta}^{-1}$ tomatoes (Baganz et al., 2020) as well as a 16 story residential building with around 380 residents (cf. Table 3). Environmental and economical boundary conditions are neglected in this example. Some CE-resources are used within the site area (greywater), while others are mediated via utility grids (power, district heating).

In Table 3 the hypothetical quantities of available resources are given annually, and whether proximity is needed for using a resource is indicated. This kind of site resource inventory is intended to support companies when making their business location decisions or to support local authorities in the planning process. 
Table 2. Resource catalogue excerpt - example records for aquaponics as a CE entity.

\begin{tabular}{|c|c|c|c|c|c|c|c|}
\hline Resource type & Direction & Grid & Resource subtype & Unit & Reliabilty & Comment & Quality \\
\hline Electricity & IN & Power grid & Electricity & MWh & steady & & \\
\hline Thermal Energy & IN & District heating & Excess heat & MWh & steady & & \\
\hline Water & IN & & Greywater & $\mathrm{m}^{3}$ & steady & $\begin{array}{l}\text { Requirement: double pipe } \\
\text { system for house drainage }\end{array}$ & $\begin{array}{l}\text { Treatment } \\
\text { required }\end{array}$ \\
\hline Water & IN & & Stormwater & $\mathrm{m}^{3}$ & not constant & Useful: rainwater retention & $\begin{array}{l}\text { Treatment } \\
\text { required }\end{array}$ \\
\hline Biomass & OUT & & Plant leftovers & $\mathrm{t}$ & not constant & Tomato plant leftovers & \\
\hline Biomass & OUT & & Sludge & $\mathrm{t}$ & not constant & & \\
\hline Electricity & OUT & Power grid & CHP* electricity & MWh & steady & & \\
\hline Sewage & OUT & Sewerage network & Wastewater & $\mathrm{m}^{3}$ & steady & & $\begin{array}{l}\text { Specific local } \\
\text { regulations }\end{array}$ \\
\hline Thermal Energy & OUT & District heating & $\mathrm{CHP}^{*}$ heat & MWh & steady & & \\
\hline
\end{tabular}

${ }^{*}$ CHP combined heat and power unit.

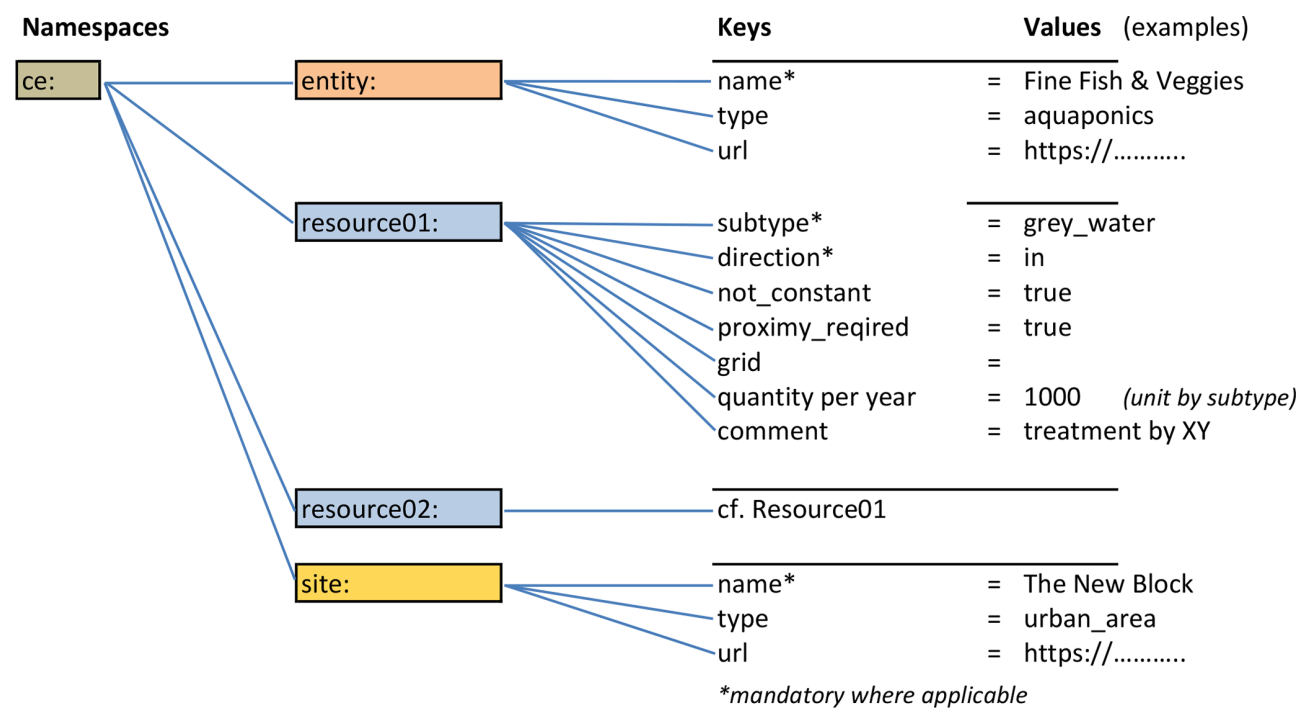

Figure 3. Proposed names for OSM tags within the namespace "ce:”.

\section{Core CE information model}

The following terms have been defined: (1) CE-resource catalogue - the total $\mathrm{CE}$ resources of a $\mathrm{CC}$, distributed via the municipal grids or in the vicinity (2) CE entity - a black box with CE-resources as input and/or output, and (3) Site resource inventory - inputs and outputs of all $\mathrm{CE}$ entities at a given location. The terms and their definitions should be discussed in order to achieve greatest possible clarity and to avoid ill-conceived concepts. For example, (1) the term entity was preferred to the terms component or unit as it is based on the Entity-Relationship-Model (Chen, 1976) in which it represents an abstract or physical object of the real world. (2) The term site was used instead of the terms location or area because of its proximity to the term building site, even if site is moved in the direction of virtual reality by the usage in the term website. (3) As the information model concerns the CE, the term CE entity was preferred to CC entity (even if all $\mathrm{CE}$ entities of a use case are within the system boundaries of the respective $\mathrm{CC}$ ).

As a result of these considerations, a core CE information model is proposed, using a newly developed taxonomy (cf. Fig. 2). First, the type of site (cf. Table 3), entity (cf. Table 1) and resource (cf. Table 2) are described, which are then used in the corresponding $\mathrm{CE}$ information elements. The arrows in Fig. 2 do not indicate resource flows but access relations between model elements as e.g. in the Unified Model- 


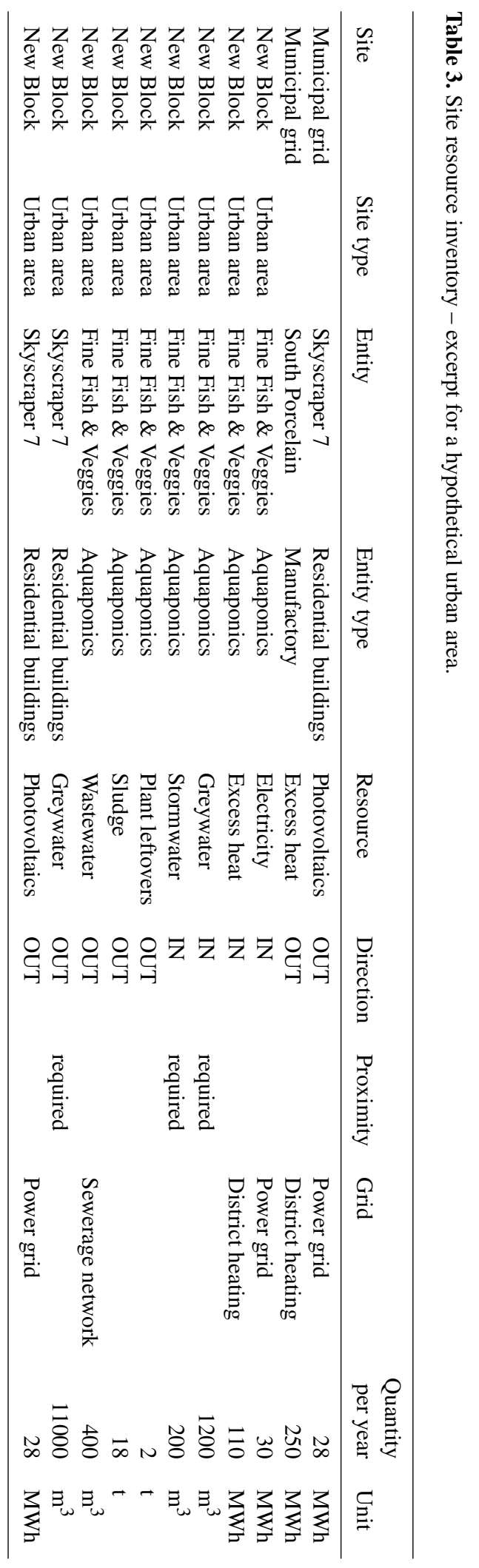

ing Language (UML) class diagram. CE sites and CE entities have a standardised information profile in this draft model, whereas the diverse $\mathrm{CE}$ resource characteristics which depend on the entity type may be described by extended resource specifications (cf. Fig. 2).

The resource usage model element then describes how the individual resources are used by the entities, whether they are input or output and whether the standard infrastructure is used. The occupancy of a site with CE entities (cf. Sect. 4) as basis of the site resource inventory can be determined by a simple GIS function.

The site resource inventory can be the basis for a site profile by automatically including additional data such as distances to resource access or other dossiers of similar information.

\section{Proposal: Implementation}

One potential data source for a site resource inventory is the geodata infrastructure maintained by municipalities, e.g. the Berlin Geodata Portal. Berlin pursues an open data policy; its Geodata Portal covers a wide range of data from different areas and is complemented by additional, topic specific portals such as the Berlin Energy Portal. The information is collected and published centrally, which has some limitations: the databases have a rather fixed information structure, a low update rate, and no possibility for error correction by the users.

User generated content (UGC) or more specifically, volunteered geographic information (VGI) is another way to access and distribute CE information, because geographical data are of importance here. A well-known platform that can be used for many different purposes is OpenStreetMap (OSM). Anyone who registers with the platform can add and change content. Maps created by OSM are "Open Data" available under the Open Data Commons Open Database License (ODbL) through the OpenStreetMap Foundation (OSMF). OSM relies heavily on tags which describe specific features of map elements. The tags are key-value pairs which can be extended by namespaces to group closely related keys.

The standard tags of OSM are of little use for information processing in the $\mathrm{CE}$, so an ongoing "CircularEconomy" project (https://wiki.openstreetmap.org/wiki/ WikiProject_CircularEconomy, last access: 1 June 2020) on OSM is improving semantic granularity by introducing specific CE-tags. This CE-project focuses on points of interest (POI) for community circular economy and Table 4 shows an excerpt of its detailed documentation.

The OSM platform represents a publicly available GIS infrastructure which could support businesses in deciding where to locate new $\mathrm{CE}$ entities. Though, since the "CircularEconomy" project is about locations relevant for consumers, it does not have the means to describe material and energy flows and therefore its tags are not sufficient to sup- 
Table 4. Some tags of the consumer OpenStreetMap project "CircularEconomy" (https://wiki.openstreetmap.org/wiki/WikiProject_ CircularEconomy\#Existing_tags, last access: 1 June 2020) (examples translated from French).

\begin{tabular}{|c|c|c|}
\hline Tag & Description & Example \\
\hline \multirow{2}{*}{$\begin{array}{l}\text { repair=assisted_ } \\
\text { self_service }\end{array}$} & mandatory & \\
\hline & It's a workshop & \\
\hline \multirow{2}{*}{$\begin{array}{l}\text { amenity= } \\
\text { workshop }\end{array}$} & mandatory & \\
\hline & $\begin{array}{l}\text { workshop most of the case. } \\
\text { Repair Café if the organizers } \\
\text { sign relative commitment }\end{array}$ & \\
\hline \multirow{2}{*}{$\begin{array}{l}\text { service_} \\
\text { times }=*\end{array}$} & mandatory & $\mathrm{Sa}[3]$ 09:00-12:00; Aug Off \\
\hline & Hours of the workshop & $\begin{array}{l}\text { Mo[1,3] Jan, Mar 09:00-12:00 } \\
\text { Th[-1] 09:00-12:30 }\end{array}$ \\
\hline name $=*$ & $\begin{array}{l}\text { mandatory } \\
\text { name of the workshop }\end{array}$ & Repair computer café \\
\hline operator $=*$ & $\begin{array}{l}\text { optional } \\
\text { the charity/organization } \\
\text { running the workshop }\end{array}$ & $\begin{array}{l}\text { Association Repair Café du } \\
\text { Pays d'Ancenis }\end{array}$ \\
\hline \multirow[t]{2}{*}{ description $=*$} & mandatory & $\begin{array}{l}\text { If you have a used electrical } \\
\text { appliance, come repair it with }\end{array}$ \\
\hline & Description & \\
\hline
\end{tabular}

port the siting of new $\mathrm{CE}$ entities within the $\mathrm{CC}$. To make the platform an effective tool for professional CE planning purposes, the range of tags describing $\mathrm{CE}$ entities and their resource flows for the purposes of CC siting must be expanded. This study therefore proposes to introduce OSM-tags for professional CE applications.

The root namespace of these new tags could be "ce:", as it is not yet used in OSM. In Fig. 3 tags for the items ce:entity and ce:site are listed, following the OSM naming conventions (https://wiki.openstreetmap.org/wiki/Tags, last access: 1 June 2020). The values are taken from the aquaponics example and include, among others (ce:entity:name=) Fine Fish \& Veggies needs (ce:resource01:subtype=) greywater as input, but these tags and corresponding values could also represent any other $\mathrm{CE}$ entity. Each $\mathrm{CE}$ entity would have a set of tags. A software solution could ensure that these tags are used correctly with respect to syntax and hierarchy, e.g. the tag "ce:site" should not be used as a property of "ce:entity" since this is determined by the spatial relationship of site and entity.

$\mathrm{CE}$ is about the coupling of resource inputs and outputs, and these resource loops must sometimes be reorganised due to both slow and rapid changes, such as in the event of failure of a CE entity. The OSM is a publicly accessible information platform that enables quickly editing and updating data, which is important in order to be responsive to changing conditions.

It would further strengthen the unity principle, i.e. the user interface and the tag naming conventions would be the same for all use cases, whereas local geodata software portals differ greatly in their user interfaces and operating philosophy. However, the possibilities may be limited for data protection or security reasons. But even then, the methodology could be applied within a municipality and the information could be released by the local authorities on request.

\section{Conclusions}

This study introduces an information model which systematically collects data to enable CE entities to effectively organise the allocation and use of resources within the $\mathrm{CC}$. The proposed method for the implementation of this model uses the publicly available geodata infrastructure of OpenStreetMap and its tagging system to operationalise the integration of CE data. A hypothetical urban aquaponic facility is used to develop exemplary new OSM tags. These tags might evolve into a CE tagging system: a new circular city geodata management approach, which would support both the public and private sector. Site resource inventories have the potential to be the link between difficult to obtain on-site information and the $\mathrm{CE}$ entities needing it. 
At this early stage in the development of the $\mathrm{CC}$, the uniform treatment of data may not yet be compulsory. However, with the envisaged extension of the CC (Langergraber et al., 2020; Daigger et al., 2016; Gravagnuolo et al., 2019), the possible upscaling of urban and peri-urban agriculture, the increased use of nature-based solutions (NBS) (Krauze and Wagner, 2019), and other elements of the CC, the number of resource interdependencies will increase to such an extent that an appropriate methodology is needed to keep track of them.

The availability and standardisation of this data would also reduce the vulnerability of the $\mathrm{CC}$ to disruptions; in the case of a CE entity failure, the information needed to find the most effective replacement of specific resource demands and provisions would be easily accessible. It remains to be seen to what extent this site-specific CE approach is suitable to simplify CC planning. This should be investigated in a further study in which the developed information model is applied in a case study with real data. One of the questions to be investigated is how the obtained information can be best used for planning issues.

The CC is an excellent concept, however in order to replace standard infrastructures on a large scale with alternative and decentralised resources, appropriate measures must be put in place to maintain secure supply chains and resilient cities. The model proposed here, which serves information exchange requirements, could be one of these measures. A start has been made, the concept and its terms have to be discussed, and further research is needed to be able to bring this idea as a safe application into practice.

Data availability. This article uses hypothetical data with no underlying research data. No further supporting data are available.

Author contributions. The author roles follow the taxonomy of CASRAI's CRediT. GB contributed with Conceptualization, Methodology, Formal analysis, Writing - original draft, Visualization, and Funding acquisition. GP contributed with Writing - review \& editing. WK contributed with Writing - review \& editing and Project administration. WL contributed with Writing - review \& editing. DB contributed with Writing - review \& editing, Project administration, and Funding acquisition. GS contributed with Writing - review \& editing and Funding acquisition. FL contributed with Supervision.

Competing interests. The authors declare that they have no conflict of interest.

Special issue statement. This article is part of the special issue "European Geosciences Union General Assembly 2020, EGU Division Energy, Resources \& Environment (ERE)". It is a result of the EGU General Assembly 2020, 4-8 May 2020.
Acknowledgements. We really appreciate the helpful constructive comments from Karel Keesman (WUR) and an anonymous reviewer.

Financial support. This research has been supported by the Belmont Forum and the European Commission (grant no. 726744).

The publication of this article was funded by the Open Access Fund of the Leibniz Association.

Review statement. This paper was edited by Sonja Martens and reviewed by Karel Keesman and one anonymous referee.

\section{References}

Albrecht, T. R., Crootof, A., and Scott, C. A.: The WaterEnergy-Food Nexus: A systematic review of methods for nexus assessment, Environ. Res. Lett., 13, 043002 , https://doi.org/10.1088/1748-9326/aaa9c6, 2018.

Baganz, G., Baganz, D., Staaks, G., Monsees, H., and Kloas, W.: Profitability of multi-loop aquaponics: Year-long production data, economic scenarios and a comprehensive model case, Aqua. Res., 51, 2711-2724, https://doi.org/10.1111/are.14610, 2020.

Blay-Palmer, A. and Donald, B.: A Tale of Three Tomatoes: The New Food Economy in Toronto, Canada, Eco. Geogr., 82, 383399, https://doi.org/10.1111/j.1944-8287.2006.tb00322.x, 2006.

Buehler, D. and Junge, R.: Global Trends and Current Status of Commercial Urban Rooftop Farming, Sustainability, 8, 1, https://doi.org/10.3390/su8111108, 2016.

Chen, P. P.-S.: The entity-relationship model - toward a unified view of data, ACM Trans. Database Syst., 1, 9-36, https://doi.org/10.1145/320434.320440, 1976.

Coutard, O. and Rutherford, J.: Beyond the Networked City, Routledge, London, UK, 2016.

Daigger, G., Newell, J., Love, N., McClintock, N., Gardiner, M., Mohareb, E., Horst, M., Blesh, J., and Ramaswami, A.: Scaling up agriculture in city-regions to mitigate FEW system impacts, University of Michigan FEW Workshop: Scaling Up Agriculture in City-Regions, 5-6 October 2015, 62 pp., available at: http://urbansustainability.snre.umich.edu (last access: 18 May 2020), 2016.

EC: A new Circular Economy Action Plan - For a cleaner and more competitive Europe, European Commission, Brussels, 20, https://eur-lex.europa.eu/legal-content/EN/TXT/?uri=COM: 2020:98:FIN (last access: 5 June 2020), 2020.

Goddek, S. and Körner, O.: A fully integrated simulation model of multi-loop aquaponics: A case study for system sizing in different environments, Agr. Syst., 171, 143-154, https://doi.org/10.1016/j.agsy.2019.01.010, 2019.

Goddek, S., Joyce, A., Kotzen, B., and Burnell, G. M.: Aquaponics Food Production Systems, Springer Nature Switzerland AG, Cham, Switzerland, 619 pp., 2019.

Gravagnuolo, A., Angrisano, M., and Fusco Girard, L.: Circular Economy Strategies in Eight Historic Port Cities: Criteria and 
Indicators Towards a Circular City Assessment Framework, Sustainability, 11, 3512, https://doi.org/10.3390/su11133512, 2019.

Howard, R. J.: Infrastructure asset management under Australian Accounting Standard 27 (AAS27), Proc. Inst. Civil Eng. Muni. Eng., 145, 305-310, https://doi.org/10.1680/muen.2001.145.4.305, 2001.

Jawahir, I. S. and Bradley, R.: Technological Elements of Circular Economy and the Principles of 6R-Based Closed-loop Material Flow in Sustainable Manufacturing, Procedia CIRP, 40, 103108, https://doi.org/10.1016/j.procir.2016.01.067, 2016.

Karimanzira, D., Keesman, K. J., Kloas, W., Baganz, D., and Rauschenbach, T.: Dynamic modeling of the INAPRO aquaponic system, Aqua. Eng., 75, 29-45, https://doi.org/10.1016/j.aquaeng.2016.10.004, 2016.

Katsou, E., Nika, C.-E., Buehler, D., Marić, B., Megyesi, B., Mino, E., Babí Almenar, J., Bas, B., Bećirović, D., Bokal, S., Đolić, M., Elginöz, N., Kalnis, G., Mateo, M.-C. G., Milousi, M., Mousavi, A., Rinčić, I., Rizzo, A., RodriguezRoda, I., Rugani, B., Šalaševičienè, A., Sari, R., Stanchev, P., Topuz, E., and Atanasova, N.: Transformation tools enabling the implementation of nature-based solutions for creating a resourceful circular city, Blue-Green Systems, 2, 188-213, https://doi.org/10.2166/bgs.2020.929, 2020.

Keesman, K. J., Körner, O., Wagner, K., Urban, J., Karimanzira, D., Rauschenbach, T., and Goddek, S.: Aquaponics Systems Modelling, in: Aquaponics Food Production Systems: Combined Aquaculture and Hydroponic Production Technologies for the Future, edited by: Goddek, S., Joyce, A., Kotzen, B., and Burnell, G. M., Springer International Publishing, Cham, 267-299, 2019.

King, L., Weidinger, J., Köhl, F., Naimer, M., and Wriege-Bechtold, A.: Zingster reloaded, edited by: King, L., Weidinger, J., Köhl, F., Naimer, M., and Barjenbruch, M., Universitätsverlag der TU Berlin, Berlin, 2015.

Kirchherr, J., Reike, D., and Hekkert, M.: Conceptualizing the circular economy: An analysis of 114 definitions, Resour. Conserv. Recyc., 127, 221-232, https://doi.org/10.1016/j.resconrec.2017.09.005, 2017.

Kloas, W., Groß, R., Baganz, D., Graupner, J., Monsees, H., Schmidt, U., Staaks, G., Suhl, J., Tschirner, M., Wittstock, B., Wuertz, S., Zikova, A., and Rennert, B.: A new concept for aquaponic systems to improve sustainability, increase productivity, and reduce environmental impacts, Aqua. Environ. Inter., 7, 179-192, https://doi.org/10.3354/aei00146, 2015.

Korhonen, J., Honkasalo, A., and Seppälä, J.: Circular Economy: The Concept and its Limitations, Ecol. Econom., 143, 37-46, https://doi.org/10.1016/j.ecolecon.2017.06.041, 2018.

Krauze, K. and Wagner, I.: From classical water-ecosystem theories to nature-based solutions - Contextualizing nature-based solutions for sustainable city, Sci. Total Environ., 655, 697-706, https://doi.org/10.1016/j.scitotenv.2018.11.187, 2019.

Langergraber, G., Pucher, B., Simperler, L., Kisser, J., Katsou, E., Buehler, D., Mateo, M. C. G., and Atanasova, N.: Implementing nature-based solutions for creating a resourceful circular city, Blue-Green Syst., 2, 173-185, https://doi.org/10.2166/bgs.2020.933, 2020.

Lohrberg, F., Licka, L., Scazzosi, L., and Timpe, A.: Urban Agriculture Europe, Architecture Urban Space, jovis Verlag GMBH, Berlin, 256 pp., 2015.
Million, A., Bürgow, G., and Steglich, A.: Roof water-farm, Sonderpublikation des Instituts für Stadt- und Regionalplanung der Technischen Universität Berlin, edited by: Million, A., Bürgow, G., and Steglich, A., Universitätsverlag der TU Berlin, Berlin, 2018.

Palm, H. W., Knaus, U., Appelbaum, S., Goddek, S., Strauch, S. M., Vermeulen, T., Hassam Jijakli, M., and Kotzen, B.: Towards commercial aquaponics: a review of systems, designs, scales and nomenclature, Aqua. Int., 26, 813-842, https://doi.org/10.1007/s10499-018-0249-z, 2018.

Proksch, G.: Creating Urban Agricultural Systems, Routledge, New york, 380 pp., 2016.

Proksch, G. and Baganz, D.: CITYFOOD: Research Design for an International, Transdisciplinary Collaboration, Technology|Architecture + Design, 4, 35-43, https://doi.org/10.1080/24751448.2020.1705714, 2020.

Proksch, G., Ianchenko, A., and Kotzen, B.: Aquaponics in the Built Environment, in: Aquaponics Food Production Systems: Combined Aquaculture and Hydroponic Production Technologies for the Future, edited by: Goddek, S., Joyce, A., Kotzen, B., and Burnell, G. M., Springer International Publishing, Cham, 523-558, 2019.

Reyes Lastiri, D., Geelen, C., Cappon, H. J., Rijnaarts, H. H. M., Baganz, D., Kloas, W., Karimanzira, D., and Keesman, K. J.: Model-based management strategy for resource efficient design and operation of an aquaponic system, Aqua. Eng., 83, 27-39, https://doi.org/10.1016/j.aquaeng.2018.07.001, 2018.

Skar, S. L. G., Pineda-Martos, R., Timpe, A., Pölling, B., Bohn, K., Külvik, M., Delgado, C., Pedras, C. M. G., Paço, T. A., Ćujić, M., Tzortzakis, N., Chrysargyris, A., Peticila, A., Alencikiene, G., Monsees, H., and Junge, R.: Urban agriculture as a keystone contribution towards securing sustainable and healthy development for cities in the future, Blue-Green Syst., https://doi.org/10.2166/bgs.2019.931, 2019.

Suárez-Eiroa, B., Fernández, E., Méndez-Martínez, G., and Soto-Oñate, D.: Operational principles of circular economy for sustainable development: Linking theory and practice, J. Clean. Product., 214, 952-961, https://doi.org/10.1016/j.jclepro.2018.12.271, 2019.

Sukhdev, A., Vol, J., Brandt, K., and Yeoman, R.: Cities in the Circular Economy: The Role of Digital Technology, Ellen MacArthur Foundation ANBI, Cowes, UK, 10, available at: https://www.ellenmacarthurfoundation.org/assets/downloads/ Cities-in-the-Circular-Economy-The-Role-of-Digital-Tech.pdf (last access: 5 June 2020), 2019.

UN: About the Sustainable Development Goals - United Nations Sustainable Development, United Nations, New York, https://www.un.org/sustainabledevelopment/ sustainable-development-goals/ (last access: 5 June 2020), 2019.

Willett, W., Rockström, J., Loken, B., Springmann, M., Lang, T., Vermeulen, S., Garnett, T., Tilman, D., DeClerck, F., Wood, A., Jonell, M., Clark, M., Gordon, L. J., Fanzo, J., Hawkes, C., Zurayk, R., Rivera, J. A., De Vries, W., Majele Sibanda, L., Afshin, A., Chaudhary, A., Herrero, M., Agustina, R., Branca, F., Lartey, A., Fan, S., Crona, B., Fox, E., Bignet, V., Troell, M., Lindahl, T., Singh, S., Cornell, S. E., Srinath Reddy, K., Narain, S., Nishtar, S., and Murray, C. J. L.: Food in the Anthropocene: the EATLancet Commission on healthy diets from sustainable food sys- 
tems, The Lancet, 393, 447-492, https://doi.org/10.1016/S01406736(18)31788-4, 2019.

Witzel, O., Wilm, S., Karimanzira, D., and Baganz, D.: Controlling and regulation of integrated aquaponic production systems - An approach for a management execution system (MES), Inform. Process. Agr., 6, 326-334, https://doi.org/10.1016/j.inpa.2019.03.007, 2019. 